\title{
Segregation of oil palm fruit ripeness using color sensor
}

\author{
Aiman Mustaffa ${ }^{1}$, Faiz Arith ${ }^{1}$, Nurin Izzati Fauzi Peong ${ }^{1}$, Nurul Rafiqah Jaffar ${ }^{1}$, \\ Evelyn Larwy Linggie ${ }^{1}$, Ahmad Nizamuddin Mustafa ${ }^{2}$, Fara Ashikin Ali ${ }^{2}$ \\ ${ }^{1}$ Faculty of Electronic and Computer Engineering, Universiti Teknikal Malaysia Melaka (UTeM), Melaka, Malaysia \\ ${ }^{2}$ Faculty of Electrical and Electronic Engineering Technology, Universiti Teknikal Malaysia Melaka (UTeM), Melaka, Malaysia
}

\begin{tabular}{l} 
Article Info \\
\hline Article history: \\
Received Jun 10, 2021 \\
Revised Nov 11, 2021 \\
Accepted Nov 30, 2021 \\
\hline
\end{tabular}

Keywords:

Arduino

Oil palm fruit

Ripeness

Segregation system

TCS3200 color sensor

\begin{abstract}
Oil palm is an important industry that has contributed to income and support to the economic sector especially for Malaysia and Indonesia. However, most of the equipment in the oil palm industry is still operated manually. This work developed a system to separate bunches of oil palm fruit using color sensors according to maturity level. Fruit color plays a decisive point in determining fruit maturity. Here, a specific threshold point of red green blue (RGB) was obtained for the determination of the maturity level of oil palm fruit. Point values of $<120,120<\mathrm{x}<150$ and $>150$ represent the maturity levels of unripe, under ripe and ripe, respectively. This paper is the first to report the RGB points for use in the development of automated oil palm segregation system in the oil palm plantation industry. Thus, this paper will pave the way in producing an accurate and reliable oil palm separation system, which in turn has a positive effect in reducing human error. In the future, a set of sensors is proposed to detect a bunch of the oil palm fruits. This further can speed up the segregation process and more suitable for adaptation to the industry.
\end{abstract}

This is an open access article under the CC BY-SA license.

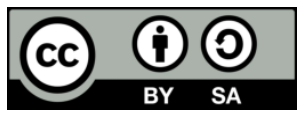

\section{Corresponding Author:}

Faiz Arith

Faculty of Electronic and Computer Engineering

Universiti Teknikal Malaysia Melaka (UTeM)

Hang Tuah Jaya, 76100, Durian Tunggal, Malaysia

Email: faiz.arith@utem.edu.my

\section{INTRODUCTION}

Oil palm plantations are very prominent and play a major role in the economy for countries such as Malaysia and Indonesia where oil palm can grow fertile and fast [1], [2]. Most of these palm oil products are used for food, detergent and as a biofuel. For the food sector, these crops can be contributing to the food sector for the use of cooking oil, shortening and margarine. Oil palm is a productive crop with oil yield per hectare per year which is much larger than other oil crops. High oil palm yield means palm oil needs a small growth area compared to other competing oil crops and thus become a very attractive source of income. The oil composition of the palm kernel oil is used as the main ingredient in the production of non-hydrogenated trans-free margarine. Globally, $90 \%$ of palm oil is used for food-related product. Furthermore, this palm kernel can be used for personal care products in liquid or cream formed [3].

In the palm oil industry, Malaysia is the second largest global producer after Indonesia and it has been a major economic source for the country for the past few decades. Palm oil cultivation plan was started in 1960s to reduce Malaysia's dependence on rubber and tin under the government's diversification program [3], [4]. Malaysia also became the largest palm oil exporter in the world during the same period. The government nationalized three major companies for oil palm which were Guthrie, Golden Hope and Sime 
Darby in the year 1980 [4]. Based on statistics, up to 2016, the plantation area of palm oil has increased to $57,400 \mathrm{~km} 2$ in all Malaysian states as shown in the Table 1 [4].

Table 1. Plan oil plantation area in Malaysia by state in 2016

\begin{tabular}{lccc}
\hline \multicolumn{1}{c}{ State } & Plantation Area (hectares) & Percentage of Total Plantation Area & Percentage of State Area \\
\hline Sabah & $1.551,714$ & $27.0 \%$ & $21.1 \%$ \\
Sarawak & $1,506,769$ & $26.3 \%$ & $12.1 \%$ \\
Johor & 745,630 & $13.0 \%$ & $38.8 \%$ \\
Pahang & 732,052 & $12.8 \%$ & $20.3 \%$ \\
Perak & 397,908 & $6.9 \%$ & $18.9 \%$ \\
Negeri Sembilan & 178,958 & $3.1 \%$ & $26.8 \%$ \\
Terengganu & 171,943 & $3.0 \%$ & $13.2 \%$ \\
Kelantan & 155,458 & $2.7 \%$ & $10.3 \%$ \\
Selangor & 138,831 & $2.4 \%$ & $17.1 \%$ \\
Kedah & 87,786 & $1.5 \%$ & $33.7 \%$ \\
Melaka & 56,149 & $1.0 \%$ & $13.5 \%$ \\
Penang & 14,135 & $0.2 \%$ & $9.2 \%$ \\
Perlis & 652 & $0.0 \%$ & $0.8 \%$ \\
\hline
\end{tabular}

From Table 1, it can be concluded that in Malaysia, the oil palm fruit produced is in large volume. However, oil palm plant companies are still lagging behind in the autonomous system and use manpower in most of their production processes [5], [6]. One of them is the palm oil ripeness segregation system. The fully ripe fruit consists of high-quality oil compared to the unripe and overripe fruit. In addition, it also contains low free fatty acids which healthy foods [7]. Therefore, it is most important to determine that the bunch of fruit that are harvested and collected are ripe. The possibility of error in determining the maturity of the fruit can affect in higher harvesting costs and substantial losses for the industry [8].

At present, there are many automated systems based semiconductor sensor devices have been developed [9]-[13]. In agriculture industry, such technology is used to simplify the process for instance, nutrient prob [14] loose fruit picking machines [15], [16] and fruit sorting machines [17]-[19]. This automated system is powered by a microcontroller and Arduino. Such system can be developed by using the electronic components such as a motor (plastic gear motor and direct current motor), color sensor, infrared sensor, motor shield and Arduino Mega 2560.

Many previous studies have been done to develop an autonomous segregation system for the fruits and vegetables based on color [1], [20]. Premachandra et. al. [21] developed a pick and place system based on color and size using RGB and hue, saturation, value (HSV) values. Color sensor is used to absorb the amount light reflected by an object and converted into frequency. The objects are sorted and placed into two convenyor assisted with image processing algorithm. However, this system only can perform with duochrome color objects for the segregation process. Meanwhile, Gaikar et. al. [22] uses audio as the output signal. Initially, the sensor detects the color of the object and the RGB serial data is generated and sent to the Arduino microcontroller. Then the microcontroller will read the received data and provides the output in form OS audio while the LCD will display the type of color. Finally, the audio output is produced through the speakers after the voice recorder records and recognizes the color name. Moreover, Raspberry Pi has also been used as the control unit for the segregation system with image processing algorithm of Phyton and the application of K-means cluster [23]. This system able to segregate the object based on the color, shape and size in real time. These features are robust and best to be embedded into the industry. However, system that utilize RGB color sensor has not been extensively studied. Although the use of RGB sensors is conventional, but a detailed study can provide the desired improvement and its accuracy can be improved. The use of such sensors can save a lot of operating and installation costs, and in turn provide added value to the profits of the oil palm industry.

In this regard, this work has developed an automation system that can separate the oil palm fruit based on its ripeness. Based on this system, color sensor will detect the color of oil palm fruit and a servo motor moves the ripe and unripe fruit to the appropriate production flow. The accuracy of the system will also be measured using light intensity feature.

Normally, 30 months is needed for an oil palm to grow before it can be harvested after being planted for the first time. Then, it can bear fruit for the next 20 to 30 years [24]. The oil palm fruit can be categorized by 3 types of grades which are unripe, ripen, and overripe as shown in Figure 1. Ripe fruit can be harvested from trees using a sickle or machete to process for crude oil production. While the unripe fruit must be left until fully ripe.

Typically, the method used to determine whether a bunch of ripe fruit is by observing the number of loose fruits on the ground or the number of loose fruit sockets in the bunch [25]. This method is used for tall 
trees because it is difficult to determine the ripeness of the fruit by using human vision. Meanwhile, for low trees, the harvester can observe the color of the fruit bunches.

Another concept for determining fruit maturity by looking at the color of the bunch. The most important is the color of the fruit because some researchers conclude that the color of oil palm fruit is correlated with the content of fruit oil [24]. There are two oil palm genes, named Nigrescens and Virescens shown in Figure 2(a) and Figure 2(b), respectively [8]. Both have completely different color changes from unripe to overripe. Nigrescens is the most widely grown type in Malaysia where it shows a yellowish-red fruit color after ripening.

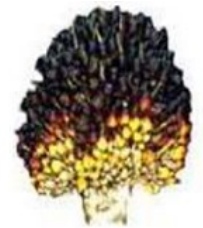

Under ripe

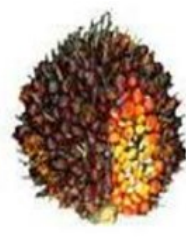

Ripe

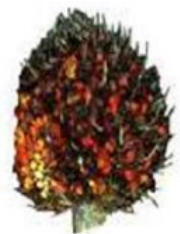

Overripe

Figure 1. Oil palm fruit ripeness corresponding to its color

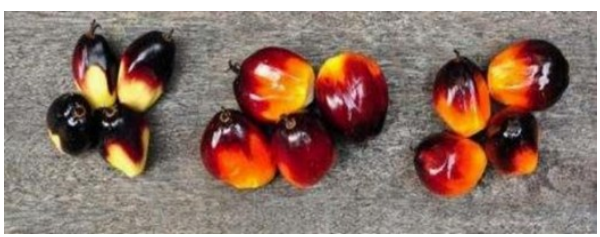

(a)

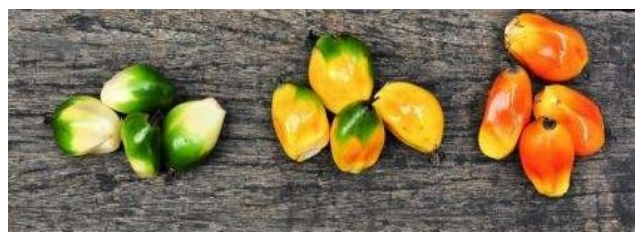

(b)

Figure 2. The color changes from unripe (left) to overripe (right) for (a) Nigrescens oil palm and

(b) Virescens oil palm

Nigerescens have a similar red color before and after ripening which makes the fruit maturity difficult to determine with the naked eye [8]. Significant differences can be seen at the ends of the oil palm fruit. The color of ripe fruit is dark red at the base while at the tip of the fruit is yellow color. As for the unripe fruit, the ends of the fruit are dark purple and yellow at the base. There is a dark red color between purple and yellow. The overripe fruit has a darker red color at the base and the yellow color at the tip becomes orange.

Meanwhile, Virescens has a green-orange fruit color when unripe, the color is bright green-green and turns greenish-yellow when ripe. Overall, it will change from green to orange indicating the ripeness of the fruit and this difference can be seen obviously and allows the separation process to be perform.

RGB color is one of the most important criteria for determining the ripeness of fruits or vegetables. In the agricultural industry, most of the grading systems used based on the red, green and blue color model to perform the segregation process. In general, color can be seen by the human eye but it also depends on the light reflected on the surface of the object [25].

According to [26], RGB color can be characterized by breaking down the measure of red, green, and blue substance of the color apparent as shown in Figure 3. At the point, when an object is brought to the detection range of the color sensors, contingent upon their voltage yield of each of the sensor, the color can be distinguished [26]. Along with a good lighting and programmed system, the accuracy and precision of segregation process will be improved.

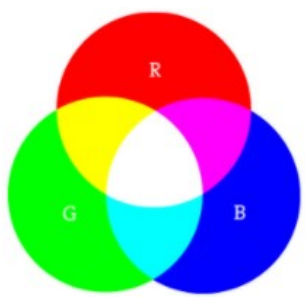

Figure 3. RGB color 


\section{METHODOLOGY}

This work can be categories into two parts namely as hardware and software development. Color sensors and the microcontroller were purchased from the market for hardware parts. The latter development was generated by the state-of-the-art software design of the Arduino. Both parts were combined and embedded to produce a well functional segregation system for this work.

\subsection{Hardware}

In this work, Arduino Mega 2560 microcontroller and programmable color light to frequency converter converter (TCS 3200) color sensor were used as the main brain and color detector device respectively. The schematic circuit with the outer connection to the hardware is shown in Figure 4. In addition, a conveyor system is also developed for the purpose of testing the prototype functionality. The TT geared motors generated from dry cell are used to move the conveyor carrying the oil palm fruits. Then the moving oil palm fruits will undergo the color determination process for their ripeness. The sensor TCS3200 which placed vertically on the conveyer will detect the color and provide a set of data in term of light intensity to the microcontroller. The Arduino Mega microcontroller will identify the ripeness level of the oil palm fruits and produced a serial data of RGB color range. Finally, servo motor that acts as the separator arm will drive the oil palm fruit according to its ripeness level into the appropriate container.

In principle, the TCS3200 color sensor can detect and measure the color range. This sensor consists of a sensor chip with 4 LEDs, where it is used to encompass a photodetector array that can detect and measure a nearly limitless range of colors. The color sensor detects the color of the oil palm fruits using the photodiode and convert into frequency before yields the range of the color. However, in order to determine the color accurately, a suitable and close environment is needed. The color sensor is attached vertically facing the conveyor inside a medium size box as shown in Figure 5(a). The conveyor will be connected to two TT geared motors at each end of the conveyor to move the oil palm fruit. External or interference light exposure can be avoided by such close environment. Apart from that, the distance between of the color sensor and the oil palm fruit is most important to consider, because there are limitations for the sensor. The distance is set to be $15 \mathrm{~mm}$ after several optimization processes.

Figure 5(b) shows the plan view of the prototype where two containers are placed beside and at the end of the conveyor. The former container is for ripen fruit and the latter for the unripe fruit. There are a servo motor serves as an arm and there are two categories of the output product either ripe or unripe oil palm fruits.

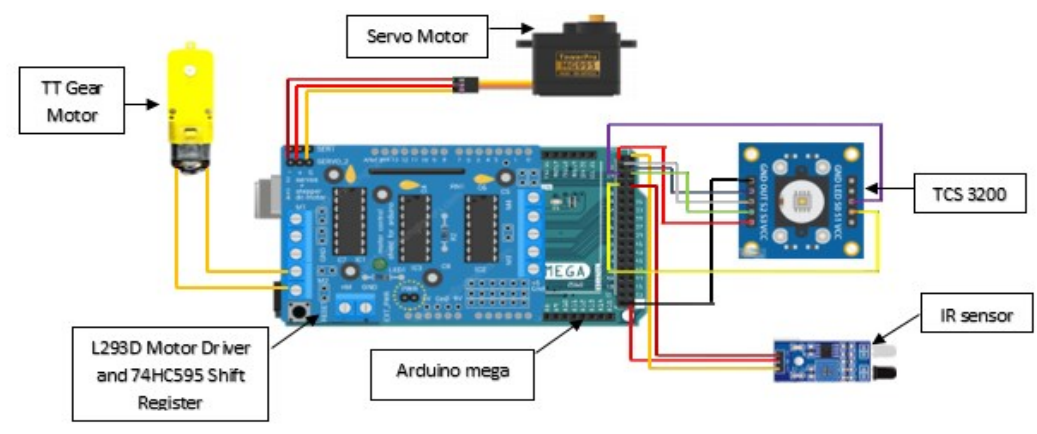

Figure 4. Schematic circuit with outer connection to the hardware

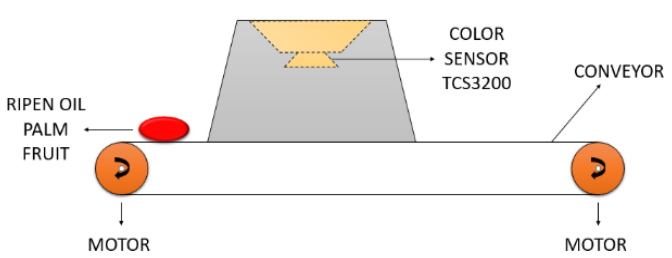

(a)

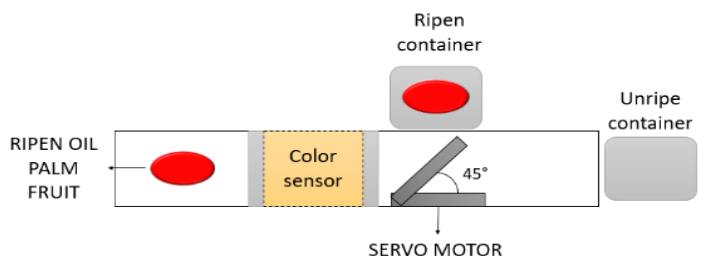

(b)

Figure 5. The prototype of oil palm fruit segregation system from (a) cross sectional view and (b) plan view

\subsection{Software}

This system is using Arduino Mega 2560 as the main controller to develop software design. It is an interface for user to create the program for control and support their systems. All the inputs and outputs 
components are declared in certain code. In this works, the code is create using arduino integrated development environment (IDE) software in JAVA language. Figure 6 shows a complete prototype of this work. The oil palm fruits are placed at the starting point and move along the conveyor through a color sensor box consisting of an IR sensor and a color sensor. The conveyor will stop for three seconds to allow enough time for the color sensor to detect the color of the oil palm fruit. After the ripeness is defined, the servo motor will move to a position of $0^{\circ}$ or $45^{\circ}$ to push the fruit that has been identified as ripe or unripe into the proper container.

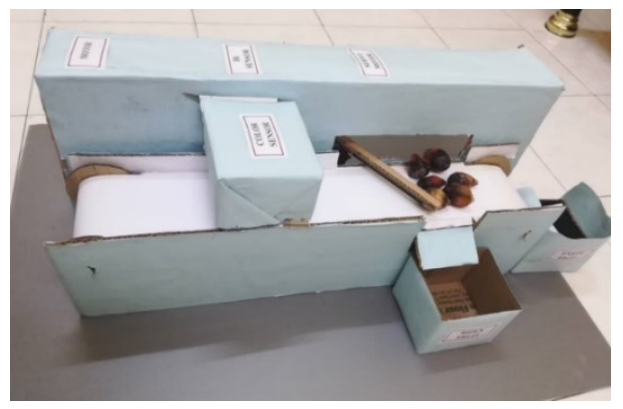

Figure 6. Prototype of the oil palm fruit segregation system

\section{RESULTS AND DISCUSSION}

\subsection{Ripe fruit}

The functionality and accuracy of this system is tested by using several samples that have been identified as ripe and unripe product. There are four types of oil palm fruits selected in this experiment. The first and second oil palm fruits are ripe as their color have turn into yellow and dark red at the tips and base respectively. The developed system has successfully detected and categories them as ripe fruits with RGB range value of above 150 indicating a strong signal of ripen as depicted in Table 2 for fruit bunch in Figure 7(a) and Figure 7(b), respectively. These experiments have been repeated three times to ensure the accuracy of the system is immaculate and also for statistical purpose.

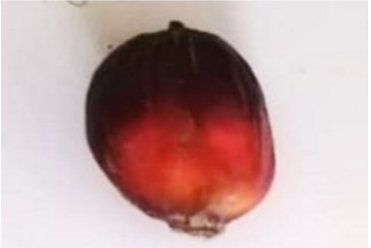

(a)

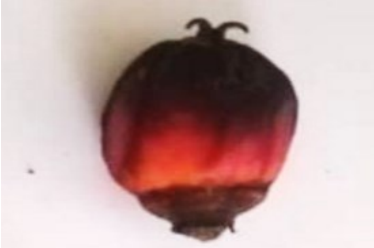

(b)

Figure 7. Image for the (a) first sample of ripe fruit and (b) second sample of ripe fruit

Table $2.1^{\text {st }}$ ripen fruit detected range

\begin{tabular}{cccccc}
\hline Test & & R & G & B & Output \\
\hline $\begin{array}{c}\text { First } \\
\text { sample } \\
\text { (a) }\end{array}$ & First & 157 & 189 & 154 & Ripe \\
& & & & & \\
& Second & 166 & 184 & 158 & Ripe \\
$\begin{array}{c}\text { Second } \\
\text { sample }\end{array}$ & First & 161 & 178 & 156 & Ripe \\
(b) & & & 183 & 151 & Ripe \\
& Second & 150 & 172 & 152 & Ripe \\
& Third & 156 & 193 & 162 & Ripe \\
\hline
\end{tabular}

\subsection{Unripe fruit results}

Unripe oil palm fruits as shown in Figure 8(a) and Figure 8(b), the system also successfully identified them as unripe products and moved them into the appropriate container. The RGB range values indicate that the unripe oil palm fruits produce fewer detection values with most of them are less than 120 points even after repeated for three times as display in Table 3. Both results of the ripe and unripe oil palm fruits have proved that the developed segregation system is functional properly. After repeated the measurements for three times, the system shows a consistent result indicating that it is reliable.

The threshold value obtained is fairly higher than previously reported but shows a similar trend where the value increases in parallel from unripe to ripe fruit. Jaffar et. al. [27] and Alfatni et. al. [28] reported that the threshold values for $\mathrm{R}, \mathrm{G}$ and $\mathrm{B}$ were 80,50 and 40 , respectively, for ripe fruit bunches. Meanwhile, for unripe fruit bunches, the threshold values were slightly lower at 10 points compared than that to ripe fruit. However, the values between the two categories are overlapping which indicates that there is ambiguity. Recently, RGB image analysis assisted by backscattering imaging demonstrated slightly higher average threshold values of 88 and 92 for unripe and ripe fruit bunches, respectively [29]. In addition, a good coefficient above 0.8 was recorded proving that its classification is quite accurate and acceptable. Above 
findings show that the threshold values are varied, depend on the RGB tools and measurement system. However, threshold value classification is required for precision to avoid uncertainty.

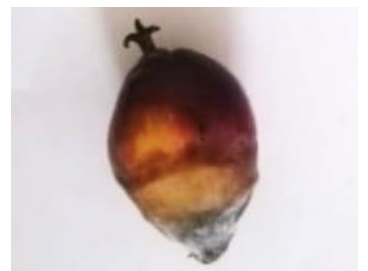

(a)

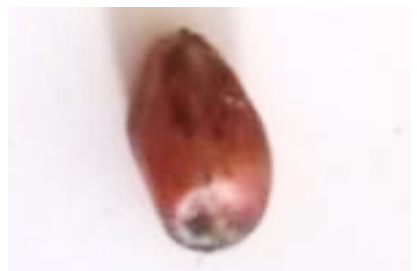

(b)

Figure 8. Image for the (a) first sample for unripe fruit and (b) second sample for unripe fruit

Table $3.1^{\text {st }}$ unripe fruit detected range

\begin{tabular}{|c|c|c|c|c|c|}
\hline Test & & $\mathrm{R}$ & $\mathrm{G}$ & B & Output \\
\hline \multirow{3}{*}{$\begin{array}{c}\text { First } \\
\text { sample } \\
\text { (a) }\end{array}$} & First & 92 & 92 & 74 & Unripe \\
\hline & Second & 90 & 90 & 72 & Unripe \\
\hline & Third & 105 & 102 & 81 & Unripe \\
\hline \multirow{3}{*}{$\begin{array}{l}\text { Second } \\
\text { sample } \\
\text { (b) }\end{array}$} & First & 116 & 115 & 95 & Unripe \\
\hline & Second & 119 & 120 & 102 & Unripe \\
\hline & Third & 105 & 102 & 81 & Unripe \\
\hline
\end{tabular}

\section{CONCLUSION}

In this work, an automatic segregation system for oil palm fruit using color sensor has been successfully developed. The process of segregation is based on the ripeness color of the fruit particularly for Nigerescens type. The system has been tested for four samples. This experiment has been performed in separating the ripe, under ripe and unripe oil palm fruits quantitatively using RGB range value. This process was repeated 3 times, and the results were almost identical, i.e., very encouraging. Based on the RGB data series, the ripe oil palm fruit showed a value exceeding 150, while for the unripe fruit showed a value less than 120 for all tests. The difference between the two characteristics of the fruit is very significant with a difference of the value of 30 and can be categorized as under ripe. This indicates that the probability of an error to occur in determining the characteristics of the fruit is slim and thus made this system more reliable and robust. In the future, a set of sensors is proposed to detect a bunch of the oil palm fruits. This further can speed up the segregation process and more suitable for adaptation to the industry. Furthermore, the image processing technology also great to introduce for the segregation system.

\section{ACKNOWLEDGEMENTS}

This research was funded by a short-term grant from Universiti Teknikal Malaysia Melaka, Malaysia (PJP/2020/FTKEE/PP/S01748).

\section{REFERENCES}

[1] D. J. Lee, J. K. Archibald, and G. Xiong, "Rapid color grading for fruit quality evaluation using direct color mapping," IEEE Trans. Autom. Sci. Eng., vol. 8, no. 2, pp. 292-302, 2011, doi: 10.1109/TASE.2010.2087325.

[2] A.-Khowarizmi, I. R. Nasution, M. Lubis, and A. R. Lubis, "The effect of a secos in crude palm oil forecasting to improve business intelligence," Bull. Electr. Eng. Informatics, vol. 9, no. 4, pp. 1604-1611, 2020, doi: 10.11591/eei.v9i4.2388.

[3] R. Rasiah and A. Shahrin, "Development of Palm Oil and Related Products in Malaysia and Indonesia," no. Malaysia 1986, 2001.

[4] A. Kushairi, R. Singh, and M. Ong-Abdullah, "The oil palm industry in Malaysia: Thriving with transformative technologies," $J$. Oil Palm Res., vol. 29, no. 4, pp. 431-439, 2017, doi: 10.21894/jopr.2017.00017.

[5] S. N. Sowat, W. I. Wan Ismail, M. R. Mahadi, S. K. Bejo, and M. S. M. Kassim, "Trend in the development of oil palm fruit harvesting technologies in Malaysia," J. Teknol., vol. 80, no. 2, pp. 83-91, 2018, doi: 10.11113/jt.v80.11298.

[6] M. R. Khalid, "Mechanising Oil Palm Loose Fruits Collection - a Review," J. Oil Palm Res., vol. 33, no. March, pp. 1-11, 2020, doi: 10.21894/jopr.2020.0069.

[7] A. S. H. Ong and S. H. Goh, "Palm oil: A healthful and cost-effective dietary component," Food Nutr. Bull., vol. 23, no. 1, pp. 11-22, 2002, doi: 10.1177/156482650202300102.

[8] R. Singh et al., "The oil palm VIRESCENS gene controls fruit colour and encodes a R2R3-MYB," Nat. Commun., vol. 5, no. May, pp. 1-8, 2014, doi: 10.1038/ncomms5106.

[9] M. A. Azhari, F. Arith, F. Ali, S. Rodzi, and K. Karim, "Fabrication of low cost sensitized solar cell using natural plant pigment dyes," ARPN J. Eng. Appl. Sci., vol. 10, no. 16, pp. 7092-7096, 2015.

[10] A. W. Setiawan, R. Mengko, A. P. H. Putri, D. Danudirdjo, and A. R. Ananda, "Classification of palm oil fresh fruit bunch using multiband optical sensors," Int. J. Electr. Comput. Eng., vol. 9, no. 4, pp. 2386-2393, 2019, doi: 10.11591/ijece.v9i4.pp2386-2393.

[11] S. H. M. Suhaimy, N. Ghazali, F. Arith, and B. Fauzi, "Enhanced simazine herbicide degradation by optimized fluoride concentrations in TiO2 nanotubes growth," Optik (Stuttg)., vol. 212, no. February, p. 164651, 2020, doi: 10.1016/j.ijleo.2020.164651.

[12] N. S. Noorasid, F. Arith, A. N. Mustafa, M. A. Azam, S. H. Meriam Suhaimy, and O. Al-Ani, "Effect of Low Temperature Annealing on Anatase TiO2 Layer as Photoanode for Dye-Sensitized Solar Cell," Przeglad Elektrotechniczny, no. 10, pp. 12-16, 2021.

[13] F. Arith, S. A. M. Anis, M. M. Said, and C. M. I. Idris, "Low cost electro-deposition of cuprous oxide P-N homo-junction solar cell," Adv. Mater. Res., vol. 827, pp. 38-43, 2014, doi: 10.4028/www.scientific.net/AMR.827.38.

[14] S. Dudala, S. K. Dubey, and S. Goel, "Microfluidic Soil Nutrient Detection System: Integrating Nitrite, pH, and Electrical Conductivity Detection,” IEEE Sens. J., vol. 20, no. 8, pp. 4504-4511, 2020, doi: 10.1109/JSEN.2020.2964174. 
[15] M. Z. M. Yusoff, A. Zamri, M. Z. A. Abd Kadir, W. Z. Wan Hassan, and N. Bin Azis, "Development of integrated loose fruit collector machine for oil palm plantations," Bull. Electr. Eng. Informatics, vol. 9, no. 2, pp. 500-506, 2020, doi: 10.11591/eei.v9i2.2087.

[16] M. Z. Mohd Yusoff, "Loose Fruit Collector Machine in Malaysia: A Review," Int. J. Eng. Technol. Sci., vol. 6, no. 2, pp. 65-75, 2019, doi: 10.15282/ijets.v6i2.2909.

[17] M. S. A. Sabri, R. Endut, C. B. M. Rashidi, A. R. Laili, S. A. Aljunid, and N. Ali, "Analysis of near-infrared (NIR) spectroscopy for chlorophyll prediction in oil palm leaves," Bull. Electr. Eng. Informatics, vol. 8, no. 2, pp. 506-513, 2019, doi: 10.11591/eei.v8i2.1412.

[18] M. Haggag, S. Abdelhay, A. Mecheter, S. Gowid, F. Musharavati, and S. Ghani, "An Intelligent Hybrid Experimental-Based Deep Learning Algorithm for Tomato-Sorting Controllers," IEEE Access, vol. 7, pp. 2019, doi: 10.1109/ACCESS.2019.2932730.

[19] J. P. B. Gonzalez, F. A. P. Ortiz, and C. P. P. Rodriguez, "Mass and volume estimation of passion fruit using digital images," IEEE Lat. Am. Trans., vol. 15, no. 2, pp. 275-282, 2017, doi: 10.1109/TLA.2017.7854623.

[20] W. Castro, J. Oblitas, M. De-La-Torre, C. Cotrina, K. Bazan, and H. Avila-George, "Classification of Cape Gooseberry Fruit According to its Level of Ripeness Using Machine Learning Techniques and Different Color Spaces," IEEE Access, vol. 7, pp. 27389-27400, 2019, doi: 10.1109/ACCESS.2019.2898223.

[21] H. A. G. C. Premachandra et al., "Genetic Algorithm Based Pick and Place Sequence Optimization for a Color and Size Sorting Delta Robot," Int. Conf. Control. Autom. Robot., pp. 5-9, 2020, doi: 10.1109/ICCAR49639.2020.9108045.

[22] T. G. Gaikar, S. N. Zadokar, R. Bhandari, and S. S. Patil, "Object Sorting using Color Sensor and Arduino," no. April, pp. $483-486,2016$

[23] I. B. Mustaffa and S. F. B. M. Khairul, "Identification of fruit size and maturity through fruit images using OpenCV-Python and Rasberry Pi," Proceeding 2017 Int. Conf. Robot. Autom. Sci. ICORAS 2017, vol. 2018-March, pp. 1-3, 2018, doi: 10.1109/ICORAS.2017.8308068.

[24] B. Nambiappan et al., "Malaysia: 100 years of resilient palm oil economic performance," J. Oil Palm Res., vol. 30, no. 1, pp. 1325, 2018, doi: 10.21894/jopr.2018.0014.

[25] M. S. M. Kassim, W. I. W. Ismail, A. R. Ramli, and S. K. Bejo, "Oil palm fresh fruit bunches (FFB) growth determination system to support harvesting operation," J. Food, Agric. Environ., vol. 10, no. 2, pp. 620-625, 2012, doi: 10.1234/4.2012.3067.

[26] M. K. Shabdin, A. R. M. Shariff, M. N. A. Johari, N. K. Saat, and Z. Abbas, "A study on the oil palm fresh fruit bunch (FFB) ripeness detection by using Hue, Saturation and Intensity (HSI) approach," IOP Conf. Ser. Earth Environ. Sci., vol. 37, no. 1, 2016, doi: 10.1088/1755-1315/37/1/012039.

[27] A. Jaffar, R. Jaafar, N. Jamil, C. Y. Low, and B. Abdullah, "Photogrammetric Grading o f Oil Palm Fresh Fruit Bunches," no. 10, 2009.

[28] M. S. M. Alfatni, A. R. M. Shariff, H. Z. M. Shafri, O. M. B. Saaed, and O. M. Eshanta, "Oil palm fruit bunch grading system using red, green and blue digital number," Journal of Applied Sciences, vol. 8, no. 8. pp. 1444-1452, 2008, doi: 10.3923/jas.2008.1444.1452.

[29] M. Mohd Ali, N. Hashim, and A. S. Abdul Hamid, "Combination of laser-light backscattering imaging and computer vision for rapid determination of oil palm fresh fruit bunches maturity," Comput. Electron. Agric., vol. 169, no. November 2019, p. 105235, 2020, doi: 10.1016/j.compag.2020.105235.

\section{BIOGRAPHIES OF AUTHORS}

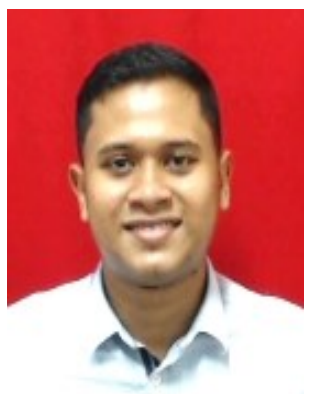

Mohammad Aiman Mustaffa (D) 81 SC $\mathrm{P}$ received the B. Eng. in Electronic and Computer Engineering from Universiti Teknikal Malaysia Melaka, Malaysia, in 2021. Currently, he is pursuing his studies in M.Sc. Electronic Engineering at Universiti Teknikal Malaysia Melaka. His research field focuses on semiconductor sensor devices related to the agricultural industry. He can be contacted at email: M022020022@student.utem.edu.my.

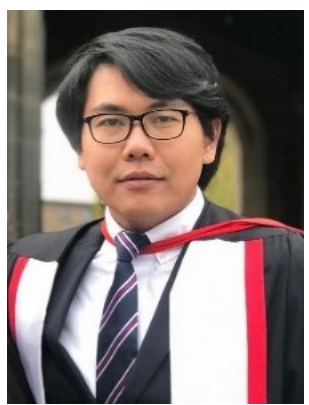

Faiz Arith (D) 8I SC P received the B. Eng. in Electrical \& Electronic Engineering from University of Fukui, Japan, in 2010. Then he obtained M.Sc in Microelectronic from National University of Malaysia in 2012 and the Ph.D. degree in Semiconductor Devices from Newcastle University, United Kingdom, in 2018. Currently, he is Senior Lecturer and the Head of Micro and Nano Electronic Research Group in Universiti Teknikal Malaysia, Melaka, Malaysia. He is the author of two book chapters, more than 30 articles, and has won several innovation competitions. His main research interest is fabrication and simulation of semiconductor devices including solar cells, MOSFETs, sensors, power semiconductor devices and optoelectonic devices. He is a Technical Editor of the Journal of Telecommunication, Electronic and Computer Engineering, and has served as reviewer in more than 10 indexed reputable journals. She can be contacted at email: faiz.arith@utem.edu.my. 


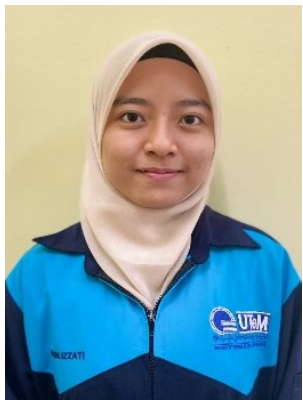

Nurin Izzati Fauzi (D) SC P received the Dip. Eng. and B. Eng in Electronic Engineering from Universiti of Teknikal Malaysia Melaka, Malaysia in 2019 and 2021, respectively. Currently, her main research focuses on semiconductor devices primarily in the simulation and fabrication of the Perovskite Solar Cell. She can be contacted at email: B021820040@student.utem.edu.my.

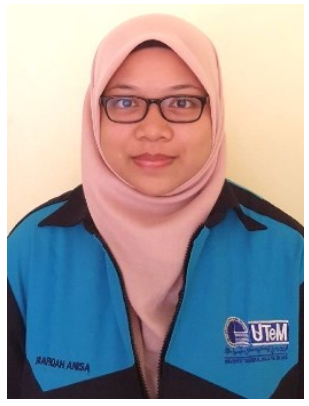

Rafiqah Anisa Jaffar (iD SA SC P received the Dip. Eng. and B. Eng in Electronic Engineering from Universiti of Teknikal Malaysia Melaka, Malaysia in 2019 and 2021, respectively. Currently, her main research focuses on semiconductor devices primarily in the simulation and fabrication of the Perovskite Solar Cell. She can be contacted at email: B021820080@student.utem.edu.my.

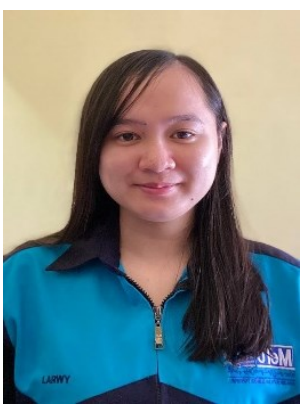

Evelyn Larwy Linggie (D) SC $\mathrm{S}$ received the Dip. Eng. and B. Eng in Electronic Engineering from Universiti of Teknikal Malaysia Melaka, Malaysia in 2019 and 2021, respectively. Her research covers on the design and analysis of IoT-Based monitoring system for predictive maintenance in manufacturing industries. She can be contacted at email: B021820068@students.utem.edu.my.

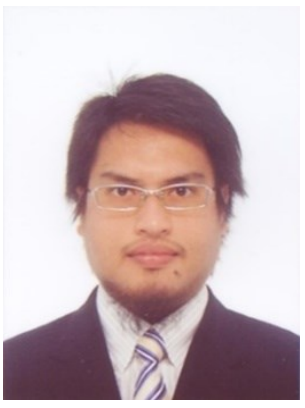

Ahmad Nizamuddin bin Muhammad Mustafa (iD) 8 SC $\mathrm{P}$ received the B. Eng. in Electrical \& Electronic Engineering from University of Fukui, Japan, in 2009. Then he obtained M. Eng. in Electrical \& Electronic Engineering from University of Fukui, Japan, in 2011. Currently, he is a Lecturer at Universiti Teknikal Malaysia, Melaka, Malaysia. He has joined Micro and Nano Electronic Research Group of UTeM and has been awarded several research grants related to the semiconductor device research. He has authored or coauthored 7 publications. His research interests include fabrication and simulation of semiconductor devices such as MOSFET, solar cells, graphene FET and GaAs optoelectronic devices. He can be contacted at email: nizamuddin@utem.edu.my.

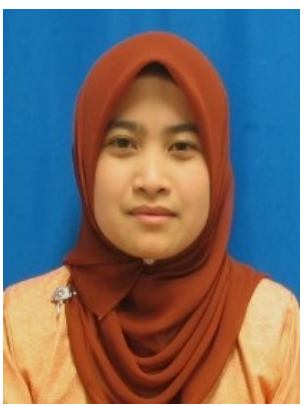

Fara Ashikin Ali (D) SC P Peceived her B. Sc. in Physics and M. Eng in Electrical and Computer Engineering from Kanazawa University, Japan, in 2008 and 2010, respectively. Then she obtained her D. Eng in Electrical and Electronics Engineering from Tokushima University, Japan, in 2018. She is currently a Senior Lecturer in Faculty of Electrical and Electronic Engineering Technology, University Teknikal Malaysia Melaka, Malaysia. Her research interests cover electrical tests of integrated circuits (ICs) and assembled printed circuit boards (PCBs), fabrication of thin film and interfacial physical properties, semiconductors and physics. She is also a Technical Editor of the Journal of Engineering and Technology. She can be contacted at email: fara@utem.edu.my. 